\title{
EMERGING TECHNOLOGIES IN PLANT PROTECTION - BIOHERBICIDES
}

\author{
B.A. AULD and C. McRAE \\ NSW Agriculture, CRC for Weed Management Systems \\ Orange Agricultural Institute, Forest Road, Orange 2800 Australia
}

\begin{abstract}
Bioherbicides have been available since the 1960s in the USA and China. The commercial bioherbicides Devine and Collego owe much of their success to the fact that they are used in irrigated agriculture. Many attempts to produce bioherbicides for pastures and dryland agriculture have been thwarted by the pathogen's requirement for extended periods of dew or rain for efficacy. In addition, mass production of filamentous fungi may pose other problems. Current developments in research to overcome constraints in bioherbicide development are discussed.
\end{abstract}

Keywords: bioherbicides, mycoherbicides, formulation, mass production, transformation

\section{INTRODUCTION}

Bioherbicides are biocontrol agents applied to weeds in similar ways to conventional herbicides. The active ingredient in a bioherbicide is, however, a living micro-organism. Most commonly the organism is a fungus, hence the term mycoherbicide is often used in these cases.

The bioherbicide tactic differs from the classical biocontrol method of weed control in which the dissemination and reproduction of the biocontrol agent is left largely up to nature. In the bioherbicide tactic, massive doses of inoculum are applied directly to all the target weeds one wishes to control. Thus the bioherbicide method requires large numbers of viable propagules and a satisfactory method of storing them so that their viability is maintained until they are required for application.

Two commercial bioherbicide products, Devine and Collegocame onto the market in the USA in the early 1980s. Since then, although new bioherbicides may have been patented and some have been registered, none have become commercial products. The many potential reasons for this have been reviewed by Auld and Morin (1995). Difficulties in mass production of propagules have often occurred and in the vast majority of cases a practical formulation to overcome the dew requirement of fungi has not been found.

\section{DEW REQUIREMENTS AND FORMULATION}

Most fungi have a requirement for dew or free water for infection and many potential bioherbicide fungi require a dew period of more than 12 hours for severe infection by the pathogen (Auld and Morin 1995) or sequential periods of dew (Walker and Boyette 1986). Moreover, a delay in the onset of dew after spraying can result in low levels of infection (Auld et al. 1988; Boyette 1994). It is no coincidence that both the successful commercial products Devine and Collego are used in irrigated situations, citrus and rice respectively.

One way of avoiding the dew period requirement problem is simply to restrict the scope of bioherbicides to irrigated agriculture, horticulture or recreation areas where there is a good deal of control of the environment, particularly water supply. In addition, the use of bioherbicides in tropical climates where humidity is high and rainfall predictable is promising (Watson 1993). However, in many agricultural situations, extended periods of dew or rainfall either do not occur or if they do, are unpredictable. Thus, in dry land agriculture, the need to overcome dew requirement is the most

Proc. 50th N.Z. Plant Protection Conf. 1997: 191-194 
challenging aspect of developing bioherbicides.

There are situations, such as injection of woody weeds or where pellets of inoculum can be applied to soil, when the aerial environment of the target weed is not so important (Dorworth 1995). However, for the majority of agricultural situations where timely control of weeds is required, liquid spray formulations appear to be the most suitable strategy.

To date, most experimental formulations have been adaptions and/or refinements of conventional pesticide formulations. These, in the main, have been found wanting not least because the active ingredient of bioherbicides is a living organism and hence it has different requirements to that of a synthetic chemical. The search for a formulation solution may come from applying technology used in other industries such as the cosmetic and personal care industry or the pharmaceutical or food or surface coating industries. All these industries deal in water based products that employ such techniques as gels, emulsions, films and encapsulation. An adaption from any of these products may provide a practical water retaining bioherbicide formulation. For example, moisturising body lotions are light, readily flowable formulations that are designed to deliver water to and retain water on the skin surface. A range of humectants, emulsions and invert emulsions have been tested as formulations for several bioherbicides with the latter showing some "in principal" promise (e.g. Amsellemet al. 1990; Boyette 1994; Connick et al. 1991; Womacket al. 1996). However, difficulties in application of these extremely viscous materials and their cost has not seen any practical use. The surface coating industries may have alot to offer in terms of dealing with overcoming application of the high viscosity emulsions. These industries focus on the thixotropic properties of paints and adhesives i.e. the flowability and stability of these products under sheer stress (e.g. vigorous stirrings).

Another advantage of looking to the food, cosmetics and pharmaceutical industries is that the formulants used in their products have already met some of the human and environment health standards which may alleviate some bioherbicide registration hurdles.

Improved formulation to overcome dew requirements of fungi may also lead to reduced inoculum dose requirements (Amsellem et al. 1990). This would be useful as mass production of fungal propagules is currently another major constraint to bioherbicide development.

\section{MASS PRODUCTION}

Spores of Collego, Devine and Biomal are all produced by submerged fermentation (Bowers 1986; Kenny 1986; Cunningham and Kuiack 1989). In submerged culture fermentation, conditions in the bio reactor such as temperature, $\mathrm{pH}$, foaming, agitation and oxygen levels can be controlled and reproduced. However, there are often problems with inadequate (or nil) sporulation and production of masses of unwanted vegetative growth.

Nutrient balance can play an important part in sporulation of fungi in submerged culture. Studies with Colletotrichum truncatum have shown how carbon concentration and carbon to nitrogen $(\mathrm{C}: \mathrm{N})$ ratio influence propagule production (Jackson and Bothast 1990). Moreover, a defined amino acid composition of the $\mathrm{N}$ source improved production of conidia (Jackson and Slininger 1993). In addition, spore fitness in terms of germination and appressoria formation rate and subsequent disease production (Schisleret al. 1991) was influenced by $\mathrm{C}: \mathrm{N}$ ratios.

Oxygen mass transfer is a major limitation for aerobic processes in submerged culture as the solubility of oxygen in water is only about $6 \mathrm{ppm}$. Thus many fungi which, in nature sporulate on the surface of plants do not readily sporulate in submerged culture. Agitation to decrease boundary layer resistance and bubbling oxygen into the culture may assist but may not be adequate for some fungi. In these cases solid state fermentation may be required or a two stage system in which mycelium from liquid culture is induced to sporulate as it dries.

Some bioherbicides have been produced on solid substrates such as wheat, straw 
(Hildebrand and McCain 1978), oat grains and corn meal (Boyette et al. 1984) but large scale systems are not readily available in the western world (Stowell 1991). Notwithstanding this, solid substrate fermentation may be the only way to mass produce some fungi and may in fact be the preferred method in some countries with a tradition of producing certain foods by solid substrate fermentation (Auld 1993).

\section{GENETIC ENGINEERING AND TOXIN PRODUCTION}

Another approach may be to transform bioherbicide fungi with genes that code for virulence factors. However, phoytotoxin production genes currently known are large gene clusters of 25 to $35 \mathrm{kbp}$. Transformation systems for fungi with large gene clusters have not been developed (Brooker et al. 1996).

However, the use of a natural phytotoxin bialophos at sub-lethal levels with low spore doses of the fungus Colletotrichum gloeosporioides $\mathrm{f}$. sp. aeschynomene transformed for resistance of bialophos has indicated synergistic interaction (Brooker et al. 1996).

There is considerable interest in the commercial world in extracting phytotoxins from micro-organisms to use as herbicides, rather than using living organisms with their inherent problems of sensitivity to the environment. Bialophos is in fact, an example of this approach. It is a metabolite of the soil microbeStreptomyces viridochromogenes and is produced by fermentation. It is marketed as Herbiace in Japan.

\section{REFERENCES}

Amsellem, Z., Sharon, A., Gressel, J. and Quimby, P.C., 1990. Complete abolition of high inoculum threshold of two mycoherbicides (Alternaria cassiae and A. crassa) when applied in invert emulsion. Phytopathol. 80: 925-9.

Auld, B.A., 1998. Potential for bioherbicides in developing countries. Proc. 10th Australian and 14th Asian-Pacific Weed Conf. Brisbane. Vol 1: 81-3.

Auld, B.A. and Morin. L., 1995. Constraints in the development of bioherbicides. Weed Technol. 9: 638-652.

Auld, B.A., McRae, C.F. and Say, M.M., 1988. Possible control of Xanthium spinosium by a fungus. Agric. Ecosyts. Environ. 21: 219-23.

Bowers, R.C., 1986. Commercialization of Collego - An industrialist's view.Weed Sci. 34: $24-5$.

Boyette, C.D., 1994. Unrefined corn oil improves the mycoherbicidal activity of Colletotrichum truncatum for hemp sesbania (Sesbania exaltata) control. Weed Technol. 8: 526-9.

Brooker, N.L., Mischke, C.F., Patterson, D.D., Mischke, S., Bruckart, W.L. and Lydon, J., 1996. Pathogenicity of bar-Transformed Colletotrichum gloeosporioides $\mathrm{f}$. $\mathrm{sp}$. aeschynomene. Biol. Control 7: 159-66.

Connick, W.J., Daigle, D.S. and Quimby, P.C., 1991. An improved invert emulsion with high water retention for mycoherbicide delivery. Weed Technol. 5: 442-4.

Cunningham, J.E. and Kuiack, C., 1989. Esterase as a marker for sporulation in Colletotrichum gloeosporioides f. sp. malvae in submerged culture. Mycol. Res. 93: 236-9.

Dorworth, C., 1995. Biological Control of Red Alder (Alnus rubra) with the fungus Nectria ditissima. Weed Technol. 9: 243-248.

Jackson, M.A. and Bothast, R.J., 1990. Carbon concentration and carbon to nitrogen ratio influence submerged culture conidiation by the potential bioherbicide Colletotrichum truncatum NRRL 13757. Appl. Environ. Microbiol. 56: 3435-8.

Jackson, M.A. and Slininger, P.J., 1983. Submerged culture conidial germination and conidiation of the bioherbicide Colletotrichum truncatum are influenced by the amino acid composition of the medium. J. Indust. Microbiol. 12: 471-22.

Kenny, D.S., 1986. Devine - The way it was developed - an industrialists view.Weed Sci. 34: 15-16.

Schisler, D.A., Jackson, M.A. and Bothast, R.J., 1991. Influence of nutrition during conidiation of Colletotrichum truncatum on conidial germination and efficacy in inciting disease on Sesbania exaltata. Phytopathol. 81: 587-90. 
Stowell, L.J., 1991. Submerged fermentation of biological herbicides. Pp 225-61. In: Microbial Control of Weeds, D.O. TeBeest (Ed.); Chapman and Hall, New York.

Walker, H.L. and Boyette, C.D., 1986. Influence of sequential dew periods on biocontrol of sicklepod (Cassia obtusifolia) by Alternaria cassiae. Plant Dis. 70: 962-3.

Watson, A.K., 1993. Current status of bioherbicide development and prospects for rice in Asia. Food and Fert. Tech. Centre, Taipei, Taiwan, Ext.Bull No. 365, 7 pp.

Womack, J.G., Eccleston, G.M. and Burge M.N., 1996. A vegetable oil-based invert emulsion for mycoherbicide delivery. Biol. Control 6: 23-8. 